\title{
ADAPTADOR DE CESTAS DE SUPERMERCADO PARA CADEIRANTES
}

\section{SUPERMARKET BASKET ADAPTER FOR WHEELCHAIR USERS}

\author{
Danielle Isabel de Souza ${ }^{1}$, Graduanda \\ André Schlemmer ${ }^{2}$, M.Sc \\ (1) Universidade do Contestado - Campus Rio Negrinho \\ e-mail: dani_isasouza@hotmail.com \\ (2) Universidade do Contestado - Campus Rio Negrinho \\ e-mail: schlemmer.andre@gmail.com
}

Design inclusivo, Acessibilidade, Adaptador.

\begin{abstract}
Através de um panorama entre o cadeirante realizando compras e os estabelecimentos obterem um produto adaptado projetamos a concepção de um adaptador. O produto adaptado aos cadeirantes apresenta características da tecnologia assistiva, design universal e centrado no usuário, que promove a inclusão social e permite ao cadeirante ter acessibilidade e conforto na hora de fazer suas compras no supermercado.
\end{abstract}

\section{Inclusive Design, Accessibility, Adapter}

Through a panorama between wheelchair user making shopping and establishments obtain adapted product we designed the conception of an adapter. The product adapted to wheelchair users show characteristics of assistive technology, universal design and user centered, which promotes social inclusion and allows wheelchair users to have accessibility and comfort when making their shopping in supermarket.

\section{Introdução}

A interação de todas as pessoas no meio comum é percebida como inclusão social, que por sua vez, defende acolher todas as pessoas independente de suas necessidades e restrições individuais, e criar soluções que ofereçam iguais condições de acesso a todos no meio físico (ROZICKI, 2003). A criação de um adaptador para cestas de supermercado possibilita aos cadeirantes, que são o foco deste projeto inclusivo, ter sua liberdade, conforto e segurança dentro de um supermercado, além de proporcionar uma reflexão sobre acessibilidade em espaços sociais e a conscientização de projetos direcionados em ambientes construídos.

Para concretizar o desenvolvimento do adaptador é necessário compreender às dificuldades dos cadeirantes em relação aos supermercados que frequentam. Buscar informações de dimensionamento dos supermercados, carrinhos, corredores, etc. Além de analisar similares de carrinhos de supermercados e dispositivos 
$16^{\circ}$ USIHC - Congresso Internacional de Ergonomia e Usabilidade de Interfaces Humano Computador

adaptados aos cadeirantes.

Diante deste contexto, para maior entendimento do projeto, buscamos entender as relações existentes entre acessibilidade e mobilidade em supermercado, tecnologia assistiva (TA) que visa a criação de dispositivos adaptados a portadores de deficiência, design centrado no usuário (DCU) e design universal, que mostram em uma visão mais ampla, a situação que se encontram os cadeirantes em relação ao meio externo e suas principais dificuldades quando vão ao supermercado.

Na sequência, apresentamos os principais conceitos teóricos inseridos neste universo proposto pelo projeto inclusivo do adaptador aos cadeirantes.

\section{Acessibilidade e Mobilidade}

Primeiramente entende-se por acessibilidade urbana, com base na NBR 9050 (2004, p. 02), a "possibilidade e condição de alcance, percepção e entendimento para a utilização com segurança e autonomia de edificações, espaços ou equipamentos urbanos".

Duarte e Cohen (2005) relatam que o espaço físico deve ser pensado de acordo com a diversidade humana, pois quanto menor o número de barreiras, maior é o acesso das pessoas com deficiência nos edifícios públicos. A Lei $\mathrm{n}^{\circ}$ 7.853/89 transfere para Estados e Municípios a responsabilidade pela adoção de normas que eliminem as barreiras de acesso das pessoas portadoras de deficiência a edificações, espaços urbanos e meios de transporte. Esta lei tem como objetivo a promoção da acessibilidade para todas as pessoas na sociedade, sem exclusão ou discriminação de qualquer pessoa independentemente de sua deficiência (BRASIL, 2016).

Esses conceitos ligados à acessibilidade e a mobilidade são fatores determinantes para o projeto inclusivo, e segundo a World Health Organization (1993, p. 192), a acessibilidade é "a capacidade do indivíduo de se mover de forma eficaz em seu entorno", ou seja, proporcionar recursos que viabilizem as condições necessárias para a realização de tarefas na vida cotidiana com independência e segurança.

\section{Design Inclusivo}

Fresteiro (2010, p. 268) explica que o design inclusivo acontece "através da construção do meio, para a não discriminação e inclusão social de todas as pessoas" proporcionando igualdade independente das restrições da deficiência.

Segundo Stainback, East e Sapon-Shevin (1994, p.489) "o objetivo da inclusão não é apagar as diferenças, mas sim permitir que todos pertençam a uma comunidade que valida e valoriza a sua individualidade", fazer com que o indivíduo sintase parte da sociedade é a maior essência da inclusão social. Para Cohen (2006), a inclusão das pessoas com deficiência na sociedade é um processo de adaptação, ou seja, as cidades se ajustam as pessoas com limitações através de projetos de acessibilidade.

Desta forma, o design inclusivo visa a adaptação dos espaços comerciais proporcionando acessibilidade e incluindo os cadeirantes na sociedade, permitindo que circulem de forma segura sem qualquer barreira ou obstáculos que impeçam sua passagem, tornando melhor a vida das pessoas com mobilidade reduzida.

\section{Tecnologia Assistiva (TA)}

De acordo com o Comitê de Ajudas Técnicas (CAT), a Tecnologia Assistiva (TA) é conceituada como:
Área do conhecimento, de característica interdisciplinar, que engloba produtos, recursos, metodologias, estratégias, práticas e serviços que objetivam promover a funcionalidade, relacionada à atividade e participação, de pessoas com deficiência, incapacidades ou mobilidade reduzida, visando sua autonomia, independência, qualidade de vida e inclusão social (CAT, 2007).

Segundo a NBR 9050 (2004, p. 04) Tecnologia Assistiva é um "conjunto de técnicas, aparelhos, 


\section{$16^{\circ}$ \\ ERGODESIGN USIHC CINAHPA}

instrumentos, produtos e procedimentos que visam auxiliar a mobilidade, percepção e utilização do meio ambiente e dos elementos por pessoas com deficiência". Aliado com esta definição, Mello (1997) afirma que a tecnologia é considerada assistiva quando auxilia no desempenho funcional do deficiente, e é capaz de reduzir incapacidades de atividades do dia-a-dia.

\section{Design Centrado no Usuário (DCU)}

Para Bainbridge (2004, p.763) o design centrado no usuário (DCU) "é um termo amplo que descreve os processos de design em que os usuários finais influenciam como um projeto toma forma". No mesmo sentido, Lowdermilk (2013, p. 35) explica que o DCU "não representa uma distração que nos impede de terminar o trabalho. Ele garante que iremos focar nos aspectos corretos: atender às necessidades dos usuários usando a solução tecnológica adequada".

Segundo Loureiro (2008) o foco no usuário utiliza técnicas e métodos para a criação de produtos, que além de possuir boa usabilidade, possam atender as reais necessidades das pessoas. Para Bersch (2013) todo o trabalho desenvolvido em um serviço de tecnologia assistiva deverá envolver diretamente o usuário, e terá como base o conhecimento de seu contexto de vida, a valorização de suas intenções e as necessidades funcionais pessoais, bem como, a identificação de suas habilidades atuais.

\section{Design Universal / Design para todos}

Da mesma forma que deve pensar no usuário, o designer precisa entender o contexto, por isso, o design universal representa o "processo de criação de produtos, dispositivos, ambientes, sistemas e processos que são utilizáveis por pessoas com o maior número possível de habilidades, operando dentro do maior número possível de situações (ambientes, condições e circunstâncias), que são comercialmente viáveis" (NULL, 2013, p. 79).

Através do design universal é possível integrar a técnica de um design com as necessidades das pessoas, oferecendo um design que não discrimine por deficiência, mobilidade, tamanho ou faixa $16^{\circ}$ Ergodesign - Congresso Internacional de Ergonomia e Usabilidade de Interfaces Humano Tecnológica: Produto, Informações Ambientes Construídos e Transporte

$16^{\circ}$ USIHC - Congresso Internacional de Ergonomia e Usabilidade de Interfaces Humano Computador

CINAHPA | 2017 - Congresso Internacional de Ambientes Hipermídia para Aprendizagem.

etária, mas possa ser pensado em um sentido mais amplo, que atenda não há um grupo de pessoas e sim a todos. (SONZA, et al. 2013).

Por outro viés, a Design for All Foundation (2016) e a PRODINTEC (2016) registram que o Design for All (em tradução livre, Design para Todos) é uma intervenção em ambientes, produtos e serviços, onde todas as pessoas, incluindo as gerações futuras, independentemente da idade, gênero, capacidades ou nível cultural, podem participar na construção da nossa sociedade, com igualdade de oportunidades, tanto na vida econômica, social, cultural e de lazer. Como também, promover acesso, uso e entendimento de qualquer parte desses ambientes, produtos e/ou serviços da forma mais independente possível.

Sendo assim, compreendemos que o design inserido nas circunstâncias de inclusão, acessibilidade e projeto com tecnologia assistiva pode promover igualdade social a todos, o que não pode passar despercebido além do cadeirante e do produto adaptado é o ambiente construído, que por sua vez, devem ser projetados ou reconstruídos de forma que se torne acessível.

\section{Materiais e Métodos}

De acordo com uma análise preliminar dos processos para a concepção de produto inclusivo adaptado, e em conformidade com a temática, definimos por adaptar a metodologia HUMBLES, que busca centrar o usuário como elemento principal no desenvolvimento de projetos, pois seus embasamentos são nas principais dificuldades e conflitos que ocorrem com o usuário e o produto, buscando seu bem estar e segurança (ARAGALL e MONTANA, 2016).

A primeira etapa é destinada em detectar oportunidades do Design para Todos $(\mathrm{H}=$ Highlight Design for All Opportunities), ou seja, realizar um estudo para concepção de objeto adaptativo para cadeirantes que auxilie na hora de fazer compras em supermercados.

A etapa seguinte é voltada para a identificação do usuário ( $\mathrm{U}=$ User Identification). Quem vai usar o 


\section{$16^{\circ}$ \\ ERGODESIGN USIHC CINAHPA}

produto, qual o interesse do usuário pelo produto? Considerando toda a diversidade humana (idade, lateralidade, limitações funcionais e etc.), e também, qual o interesse dos estabelecimentos pelo produto?

A próxima etapa é monitorar a interação ( $\mathrm{M}=$ Monitor interaction). Observar cliente-usuário e seu relacionamento, bem como, informações sobre as necessidades do usuário, expectativas, hábitos e conflitos. Além de observação de situações reais de interação do usuário nos supermercados, determinar qual sua opinião sobre produtos adaptados. Análise de queixas recebidas de usuários e entrevistas com os clientes, para determinar quais as principais dificuldades.

Para a concretização destas etapas iniciais foram desenvolvidos: protocolo de experiência dos usuários em supermercados (A), abrangendo questões referentes as principais dificuldades que um cadeirante enfrenta ao ir à um supermercado, ao nível de mobilidade dentro dos estabelecimentos, a relação da cadeira de rodas ao solo e etc.; Protocolo de análise de ambiente supermercados (B), questionando sobre a disponibilidade de dispositivos adaptados, dimensões dos carrinhos comuns e corredores, e o interesse que os estabelecimento tem em adquirir um produto adaptado. Como também uma análise dos dados coletados - relação cadeirante $\mathrm{x}$ ambiente construído $(\mathrm{C})$.

$\mathrm{Na}$ etapa quatro são definidas opções para o progresso do projeto, requer estudo exploratório e esforços necessários para avançar no design $(\mathrm{B}=$ Break Through Options). Foi utilizado para esta etapa painel de similares, análise paramétrica, geração de alternativas e definição de materiais.

Na quinta etapa denominada de soluções de layout (L = Lay Out Solutions) foi realizado mockup, prototipação e testes com usuário de forma que se gerar falhas possam ser corrigidas antes da prototipação final. $\mathrm{O}$ instrumento utilizado para a avaliação foi uma lista de critérios propostos por Null (2013), Design For All Fundation (2016) e

The Center for Universal Design (2003), que dizem respeito ao Design Universal, esses critérios $16^{\circ}$ Ergodesign - Congresso Internacional de Ergonomia e Usabilidade de Interfaces Humano Tecnológica: Produto, Informações Ambientes Construídos e Transporte

$16^{\circ}$ USIHC - Congresso Internacional de Ergonomia e Usabilidade de Interfaces Humano Computador

CINAHPA | 2017 - Congresso Internacional de Ambientes Hipermídia para Aprendizagem.

serão analisados através de testes em um ambiente real, com um cadeirante real, auxiliando na avaliação se o produto apresentará tecnologia assistiva e se é centrado no usuário.

As últimas etapas são direcionadas para

Comunicação Eficiente (E= Efficient

Communication) e Avaliar o projeto perante sucesso/êxito ( $\mathrm{S}=$ Sucesss Evaluation). Nessas etapas é necessário desenhar uma estratégia de marketing em relação aos concorrentes e o posicionamento do projeto perante o público-alvo, como também, introduzir o produto no mercado, geração de marca, mídias, embalagem e transporte. Deixamos registrado que por questão de parcerias e andamento do projeto as duas últimas etapas não estão comtempladas neste artigo.

\section{Resultados e Discussões.}

O projeto surgiu a partir da dificuldade de uma mãe em fazer compras com seu filho cadeirante em supermercados da região de Canoinhas/SC. Ao entrar em contato com a Universidade, o departamento de Design visualizou como uma necessidade da comunidade e angariou o projeto inclusivo através de bolsa de pesquisa por intermédio do Programa Institucional de Bolsas de Iniciação em Desenvolvimento Tecnológico e Inovação. O projeto teve seu início em julho de 2014, com estudo bibliográfico e analises de projetos similares e patentes de produtos adaptados.

Após os estudos preliminares, munidos das informações primordiais e metodologia definida, foi realizado um painel semântico para entender o que o produto trará as pessoas e quais os benefícios que o mesmo irá proporcionar a sociedade. A partir do painel semântico idealizamos o público-alvo, quem irá comprá-lo, quem irá usá-lo, e também de que forma será visto pelos mesmos.

O público-alvo foi definido como sendo primeiramente os supermercados, pois são os estabelecimentos que irão adquirir o produto adaptado para que os cadeirantes possam usá-lo para fazer compras.
Realização:

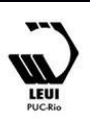




\section{$16^{\circ}$ \\ ERGODESIGN USIHC CINAHPA}

$16^{\circ}$ Ergodesign - Congresso Internacional de Ergonomia e Usabilidade de Interfaces Humano Tecnológica: Produto, Informações Ambientes Construídos e Transporte

$16^{\circ}$ USIHC - Congresso Internacional de Ergonomia e Usabilidade de Interfaces Humano Computador

CINAHPA | 2017 - Congresso Internacional de Ambientes Hipermídia para Aprendizagem.
Levando em conta que quem usará o produto serão os cadeirantes, foi necessário ter uma noção do comportamento e suas experiências com o supermercado. Por isso, realizamos um protocolo de experiência do usuário, a observação clienteusuário e informações sobre as necessidades, expectativas, hábitos e conflitos. Englobando perguntas em relação aos tipos de cadeira que utilizou; Se possui mobilidade para ir a um supermercado sozinho, com acompanhante ou auxílio de um funcionário; Nível de mobilidade dentro do estabelecimento; Vivência em executar tarefas, por exemplo, pegar produtos das prateleiras, ter acesso a todas os departamentos do supermercado e relação da cadeira de rodas ao chão do estabelecimento (aderência).

Além dos cadeirantes, realizamos um protocolo para o estabelecimento (nosso target da compra do produto), com o objetivo de compreender e descobrir fatores como: a disponibilidade de produtos com adaptações para cadeirantes, 0 dimensionamento e a acessibilidade que cadeirantes possuem quando vão fazer compras, também questões relacionadas ao

dimensionamento dos carrinhos.

Após aprovação do comitê de ética, os protocolos foram aplicados entre novembro de 2014 a maio de 2015 , os protocolos serviram como apoio para o desenvolvimento do adaptador, pois abrangeram questões de dimensionamento, materiais e posicionamento dos cadeirantes perante o ambiente construído.

Obtivemos com o protocolo das experiências dos cadeirantes um total de 11 respondentes, 08 situados na cidade de Rio Negrinho/SC, $01 \mathrm{em}$ Mafra/SC, 01 em São Bento do Sul/SC e 01 em Canoinhas/SC.

Todos tiveram experiência com cadeira manual e apenas 03 com cadeiras automáticas. O período de utilização das cadeiras em suas vidas variou de 3 até 22 anos de uso. Quanto a idade dos participantes, variaram entre 7 até 73 anos. Dos 11 respondentes, 10 vão ao supermercado acompanhados e apenas 1 vai sozinho. 8 respondentes encontram dificuldades em relação ao espaço dos supermercados, destes 8,4 responderam que o principal motivo são os lugares apertados, 1 deles os corredores estreitos, 2 a dificuldade no alcance de produtos no alto das prateleiras e 1 deles relatou que atrapalha o tamanho da sua cadeira perante o espaço construído do estabelecimento.

Fazendo uma relação das principais dificuldades mencionadas pelos 11 respondentes, 4 citaram estacionamentos inadequados, 5 a inexistência de rampas, 10 sentem dificuldades quanto as prateleiras muito altas, 5 a falta de pisos e faixas aderentes, 6 a falta de dispositivos adaptados, 7 os corredores estreitos e por fim, 5 os caixas de supermercado inadequados. Quanto ao nível de locomoção e mobilidade no supermercado, dos 11, 5 reprovam os supermercados quanto a mobilidade, 3 deles tiveram uma atitude neutra, e 3 ficam satisfeitos perante a situação.

Do protocolo direcionado aos estabelecimentos, obtivemos 11 respondentes, pela classificação do IBGE (2011) em termos de funcionários seriam todos de médio porte, 08 identificamos como porte de supermercado (porte médio/grande com maior variedade de produtos) e 03 como porte de mercado (porte menor - produtos restritos as necessidades básicas de gênero alimentício, situados em bairros da cidade); 10 dos estabelecimentos pertenciam à Rio Negrinho/SC e 01 em Canoinhas/SC;

Foram entrevistados 11 responsáveis de supermercados, destes 11 estabelecimentos comerciais nenhum deles possui dispositivos adaptados que proporcione algum tipo de ajuda ao cadeirante, na percepção dos respondentes a acessibilidade se manifesta através da ajuda de um funcionário, caso o cadeirante vá ao supermercado sozinho.

Dos 11 estabelecimentos, foram analisados 15 carrinhos de diferentes modelos e tamanhos. Nos 11 estabelecimentos os carrinhos são todos com grades, os 15 possuem suporte para empurrar e 8 são de ferro. Em relação aos materiais que são utilizados nos carrinhos, 11 são de ferro, 3 são de alumínio e 7 possuem detalhes em plástico. 


\section{$16^{\circ}$ \\ ERGODESIGN USIHC CINAHPA}

O material das rodas se subdivide em: $11 \mathrm{em}$ borracha e 3 em plástico, as rodas de todos os supermercados são giratórias, o que facilita o deslize dos carrinhos.

Todos os estabelecimentos têm uma opinião positiva em relação ao desenvolvimento e a utilização de produtos adaptados.

No que se refere aos estabelecimentos, entramos em contato com porte hipermercados em Curitiba/PR, porém não alcançamos êxito pela burocracia do contato, dificuldades no avanço e retorno de agendamentos.

Com o intuito de promover melhorias nos supermercados (ambiente construído), investigamos as dimensões das cadeiras de rodas, segundo a NBR 9050 (2015) as cadeiras de rodas manuais pesam entre $12 \mathrm{~kg}$ a $20 \mathrm{~kg}$ e as motorizadas até $60 \mathrm{~kg}$, o espaço ocupado pela cadeira de rodas é de $0,80 \mathrm{~m}$ por $1,20 \mathrm{~m}$, sendo que é necessário $1,50 \mathrm{~m}$ a $1,80 \mathrm{~m}$ para a passagem de duas cadeiras por um mesmo corredor.

Posteriormente aos protocolos, foi aplicado uma análise dimensional a partir de questões que abrangem as principais medidas e o respectivo peso dos carrinhos de supermercado, foram entrevistados 11 responsáveis de estabelecimentos nas cidades de Rio Negrinho/SC e Canoinhas/SC. Foram analisados 15 carrinhos de supermercados, apresentando uma variação de $0,80 \mathrm{~m}$ a $0,97 \mathrm{~m}$ de comprimento, $0,50 \mathrm{~m}$ a $0,55 \mathrm{~m}$, de largura e de $0,96 \mathrm{~m}$ a $1,05 \mathrm{~m}$ de altura, sendo que o peso varia entre 15 e $24 \mathrm{~kg}$.

Levando em conta a soma da dimensão da cadeira para fazer um giro completo, e a maior largura dos carrinhos encontrados, são necessários no mínimo 1,75 metros de largura nos corredores dos supermercados para apresentar acessibilidade. Se fosse considerar a passagem de 2 cadeirantes no mesmo ambiente, seria necessário de $1,50 \mathrm{~m}$ à $1,80 \mathrm{~m}$ de largura em cada corredor.

De acordo com a NBR 9050 (2015) adjunto aos resultados da análise dimensional, dos 11 supermercados que foram entrevistados, todos não $16^{\circ}$ Ergodesign - Congresso Internacional de Ergonomia e Usabilidade de Interfaces Humano Tecnológica: Produto, Informações Ambientes Construídos e Transporte

$16^{\circ}$ USIHC - Congresso Internacional de Ergonomia e Usabilidade de Interfaces Humano Computador

CINAHPA | 2017 - Congresso Internacional de Ambientes Hipermídia para Aprendizagem.

estão de acordo com os padrões necessários para promover mobilidade aos cadeirantes, que por sua vez, acabam sendo privados de frequentar certos estabelecimentos, pois encontram barreiras como corredores estreitos, falta de pisos aderentes, carrinhos de supermercado não adaptados, entre outros.

Os resultados dos protocolos e a análise dimensional foram importantes para termos um panorama sobre quais são as principais dificuldades que um cadeirante apresenta ao ir em um supermercado. Com a opinião do usuário podemos obter sugestões e melhorias que seriam necessárias no estabelecimento, para que seja totalmente acessível a qualquer pessoa, além de compreender na prática os conceitos propostos pelo Design Inclusivo, Acessibilidade, TA, DCU e Design Universal / Design para Todos, somente assim, podemos vislumbrar possíveis ideações de projetos voltados a esse segmento. Como também, eliminar ideias e alternativas de produtos que inviabilizam a aplicação de um projeto inclusivo nesses estabelecimentos entrevistados.

Diante destes resultados iniciais, entendemos que adaptar um carrinho de supermercado tornou-se inviável perante o espaço que ele ocupará nesses estabelecimentos. Por isso, colaborou para a ideação de um adaptador menor, voltado para uso das cestas de supermercado, ou seja, priorizamos questões dimensionais e a utilização do produto nos locais entrevistados neste projeto.

Partindo do pressuposto de desenvolver um adaptador para cestas de supermercado foi feita uma análise de produtos similares, juntamente com uma análise paramétrica dos produtos, para se ter ideia dos materiais utilizados, formas, tamanhos, entre outras características.

Como os usuários serão os cadeirantes, foi necessário o desenvolvimento de uma nova análise das cadeiras de rodas, para obter informações referentes à encaixes, dimensões e materiais utilizados em sua construção.

Além da análise das cadeiras de rodas, foi realizada uma análise de cestas de supermercado, 


\section{$16^{\circ}$ \\ ERGODESIGN USIHC CINAHPA}

para se obter informações referentes as suas respectivas dimensões. As novas análises contribuíram para o desenvolvimento das gerações de alternativas, mediante o dimensionamento das cadeiras e das cestas.

O produto adaptado precisa de um material que seja de boa qualidade e que dentre as suas características seja leve e de fácil moldagem. Segundo ABAL (2007 p. 10) "a leveza é uma das principais características do alumínio. Seu peso específico é de cerca de $2,70 \mathrm{~g} / \mathrm{cm}^{3}$, aproximadamente $35 \%$ do peso do aço e $30 \%$ do peso do cobre" tornando assim o material adequado para o produto a ser desenvolvido.

Como as cadeiras de rodas são feitas em tubos circulares, o adaptador terá as mesmas propriedades físicas, pois mantêm o padrão e facilita o manejo. Segundo ABAL (2007 p. 35) "os tubos de alumínio podem ser trefilados até minúsculas dimensões. Praticamente, não há limitação para as diversas formas em que o metal pode ser extrudado", da mesma forma que "o metal pode ser curvado, fresado, perfurado ou trabalhado de várias maneiras". Além dessa característica, o alumínio pode ser moldado conforme a necessidade do produto e tem fácil manipulação.

As gerações de alternativas tiveram como base fixar o produto na cadeira de rodas, para que o cadeirante fique livre do peso dos mantimentos. Das 04 gerações realizadas, foram descartadas as que não suportariam o peso de uma cesta de compras, incompatibilidade da forma/função do adaptador e critérios de conforto/segurança. A alternativa escolhida foi a que mais se aproximou do ideal, pela sua forma cilíndrica e de fácil manejo.

A alternativa final (vide figura 01) consistem em uma estrutura de alumínio tubular, com ajuste de altura através de um manipulo, fixado nas pernas frontais do adaptador, regulagem da largura com uma bucha que permite a abertura do adaptador conforme a cadeira, engates em forma de abraçadeiras que se acoplam a cadeira de rodas, e 03 alças na parte superior do adaptador (bandeja) que facilita o manejo e auxilia na segurança da $16^{\circ}$ Ergodesign - Congresso Internacional de Ergonomia e Usabilidade de Interfaces Humano Tecnológica: Produto, Informações Ambientes Construídos e Transporte

$16^{\circ}$ USIHC - Congresso Internacional de Ergonomia e Usabilidade de Interfaces Humano Computador

CINAHPA | 2017 - Congresso Internacional de Ambientes Hipermídia para Aprendizagem.

cesta de compras.

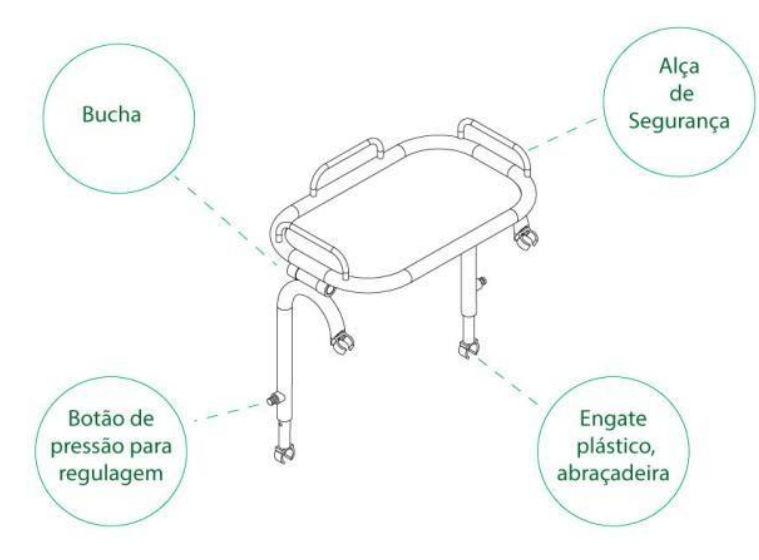

Figura 01: Alternativa final

O mockup foi feito com um material alternativo de ferro galvanizado, apenas para a definição das dimensões necessárias para que seja adaptável à cadeira de rodas.

Após a construção do mockup, foi desenvolvido o adaptador em 3D no software SolidWorks, que permitiu resolver problemas de construção e ferragens e torná-lo vigente. Como também os desenhos técnicos que visam mostrar uma perspectiva de uma vista explodida (vide figura 02), com as ferragens necessárias para a montagem, e os desenhos das peças unitariamente.

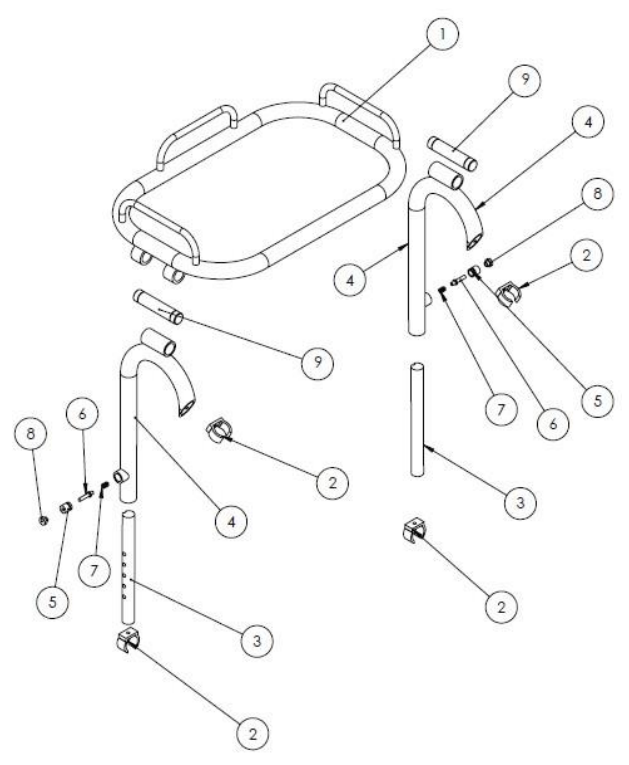

Figura 02: Vista explodida 


\section{$16^{\circ}$ \\ ERGODESIGN USIHC CINAHPA}

A prototipação do produto foi feita na Metalúrgica Arateck situada em Rio Negrinho/SC, o adaptador foi construído com tubos e chapa de alumínio, que passaram pelos processos de corte, dobra, solda, algumas peças de usinagem e também pintura.

A seguir, na figura 03 , pode ser visualizado o produto em sua fase de fabricação, ainda sem pintura, para melhor visualização do material defino no projeto.

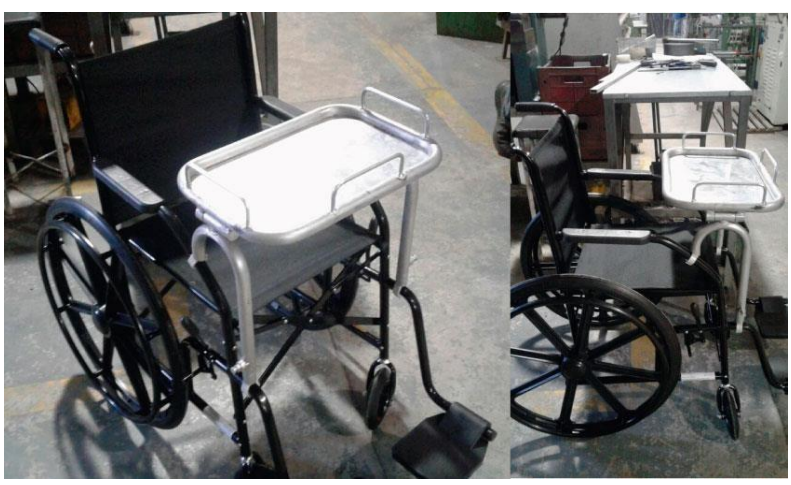

Figura 03: Protótipo do produto

Nesta etapa de prototipação, ocorreu a fase de testes com usuário real em um supermercado, o que possibilita ver de forma realista se o produto cumpriu os requisitos citados por Null (2013), que diz que o design universal deve proporcionar suporte, ser adaptável, acessível, orientado à segurança, e também de acordo com os critérios da Design for All Foundation (2016) que são: respeitoso, seguro, saudável, funcional, compreensível, sustentável, acessível e atrativo.

Perante os resultados dos critérios apresentados por Null (2013) e a Design for All Foundation (2016), observamos que o adaptador apresenta características positivas, promovendo conforto ao cadeirante na hora de fazer as compras, pois o adaptador não se apoia no corpo do usuário, apenas na cadeira de rodas, tirando do cadeirante a necessidade de empurrar ou segurar o dispositivo.

Possui em sua estrutura um material cilíndrico e arredondado o que proporciona segurança ao cadeirante, não deixando o cadeirante que tenha baixa mobilidade se machuque em cantos vivos. $16^{\circ}$ Ergodesign - Congresso Internacional de Ergonomia e Usabilidade de Interfaces Humano Tecnológica: Produto, Informações Ambientes Construídos e Transporte

$16^{\circ}$ USIHC - Congresso Internacional de Ergonomia e Usabilidade de Interfaces Humano Computador

CINAHPA | 2017 - Congresso Internacional de Ambientes Hipermídia para Aprendizagem.

Outro ponto analisado foi o espaço que o adaptador ocupa perante o ambiente construído, observamos que a cadeira de rodas ocupava um grande espaço dentro de um corredor, e o adaptador foi projetado para não ocupar mais espaço que a própria cadeira, se sobrepondo na parte superior da cadeira de rodas conforme a figura 04.

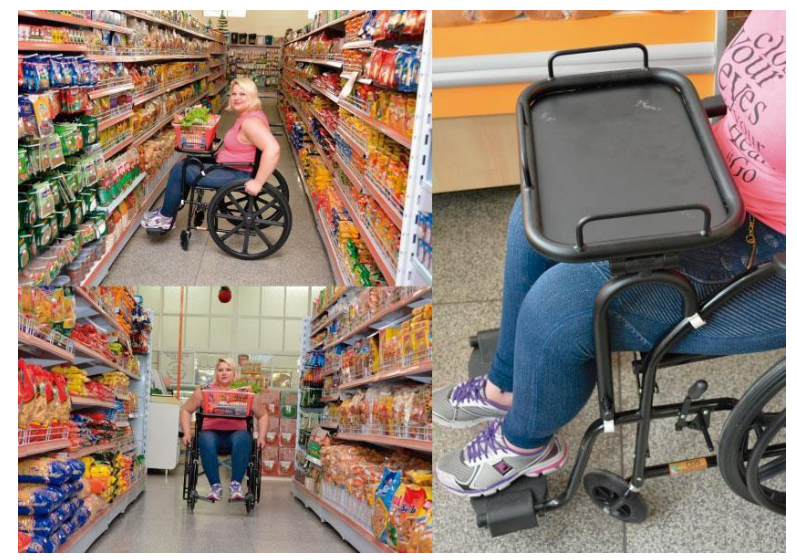

Figura 04: Teste com o usuário

\section{Considerações Finais}

$\mathrm{O}$ adaptador promove a acessibilidade e a mobilidade dos cadeirantes nos supermercados, partindo do pressuposto de que o produto de adapta a cadeira, e não ocupa um espaço superior ao da própria cadeira, possibilitando a inclusão social, fazendo com que o cadeirante se torne membro da sociedade atual e tenha autonomia para realizar suas compras no supermercado.

Das informações direcionadas ao ambiente construído, não foi apresentado elementos que contribuíssem com a mobilidade dos cadeirantes, pois a dificuldade de mudar de posição nos corredores, as barreiras em manusear produtos nas prateleiras, foram insatisfatórias do ponto de vista dos cadeirantes.

Na perspectiva da tecnologia assistiva, os 11 estabelecimentos estudados não apresentaram condições compatíveis com um mundo igualitário, visando a autonomia, independência e qualidade de vida. Em certos momentos, do panorama das experiências dos cadeirantes, foi apontado a dificuldade em realizar o simples ato de ir ao
Realização:
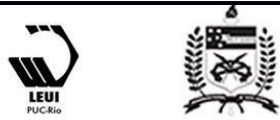


\section{$16^{\circ}$ \\ ERGODESIGN USIHC CINAHPA}

supermercado comprar.

Ao correlacionar os achados com o Design, os locais pesquisados não apresentaram características que denotam ter um Design Centrado no Usuário (DCU), nem de apresentar produtos ou serviços compatíveis com os componentes indispensáveis do Design Universal/Design para Todos.

Mesmo perante essa realidade, o Design pode transformar esse universo adaptando algo existente nos estabelecimentos, por menor que seja a mudança, a diferença contribuí para que o cadeirante se sinta parte integrante na sociedade.

$\mathrm{O}$ adaptador cumpriu com a maioria dos requisitos propostos por Null (2013), Design For All Foundation (2016) e The Center for Universal Design (2003). Os requisitos foram aplicados na configuração do produto, ou seja, inserimos no adaptador um suporte próprio, para não fazer peso sobre o usuário; adaptável com ajustes que permitem se acoplar em diferentes tamanhos de cadeiras, além de não precisar de espaço adicional entre volume e cadeira; acessível - pois o cadeirante continua livre para pegar seus produtos na gôndola; seguro e saudável - o cadeirante não tem contato permanente e direto durante o uso, e seu formato é cilíndrico e arredondado, sem cantos vivos e Material leve, de fácil montagem e ciclo de vida longo (resistente).

Por intermédio da observação do teste no usuário in loco, concluímos que o volume de produtos coletados se manteve igual ao que comporta a cesta de supermercado, sem prejudicar a visibilidade do cadeirante durante sua movimentação no estabelecimento; permanece restrito o perímetro de alcance nas gôndolas, tanto em relação da cadeira quanto as restrições específicas de cada usuário, bem com, a disposição frontal da cesta no adaptador pode apresenta certa dificuldade no manejo de pegar o produto nas gôndolas.

Por fim, entendemos que existe uma vontade de mudanças para o bem de todos na sociedade, $o$ estudo comprovou a necessidade do cadeirante, e o desejo para que os estabelecimentos proporcionem acessibilidade. Todavia, as mudanças causam $16^{\circ}$ Ergodesign - Congresso Internacional de Ergonomia e Usabilidade de Interfaces Humano Tecnológica: Produto, Informações Ambientes Construídos e Transporte

$16^{\circ}$ USIHC - Congresso Internacional de Ergonomia e Usabilidade de Interfaces Humano Computador

CINAHPA | 2017 - Congresso Internacional de Ambientes Hipermídia para Aprendizagem.

transtornos, tanto das reformas nos espaços construídos, como o custo/benefício das alterações, ou seja, comprometendo as condições de viabilidade de projetos inclusivos.

Ressaltamos que não basta apenas existir um produto adaptado, mas sim, os ambientes sofrerem mudanças ou já serem planejados pensando na acessibilidade de todas as pessoas, independentemente de sua deficiência ou condição motora, pois "para as pessoas sem deficiência a tecnologia torna as coisas fáceis. Para as pessoas com deficiência a tecnologia torna as coisas possíveis" (RADABAUGH, 1993).

\section{Bibliografia}

ABAL, Associação Brasileira do Alumínio.

Fundamentos e Aplicações do Alumínio. São Paulo, 2007

ARAGALL, F.; MONTANA, J. Universal Design

- The HUMBLES Method for User-Centred

Business. Nova Iorque/USA: Routledge, 2016.

ASSOCIAÇÃO BRASILEIRA DE NORMAS TÉCNICAS (ABNT). Norma Brasileira (NBR)

9050. Acessibilidade a edificações, mobiliário, espaços e equipamentos urbanos. $3^{\circ}$ edição. Rio de Janeiro, 2015.

BAINBRIDGE, William Sims. Berkshire

Encyclopedia of Human-Computer Interaction. Berkshire Publishing Group. Vol.2, 2004.

\section{BERSCH, Rita. Introdução à Tecnologia}

Assistiva, Material Didático, Porto Alegre, 2013.

Disponível em: 〈http:// www.assistiva.com.br>

Acesso em: 03 de junho 2016.

BRASIL. Lei no $\mathbf{7 . 8 5 3}$, de 24 de outubro de 1989 . Disponível em: <

http://www.planalto.gov.br/ccivil_03/leis/17853.ht m>. Acesso em: 01 fevereiro 2016.

CAT - Comitê de Ajudas Técnicas. Conceito de Tecnologia Assistiva apresentado pela Comissão. Ata da VII Reunião do Comitê de Ajudas Técnicas - CAT/CORDE/SEDH/PR. Realizado 
em: 13 e 14 de dez 2007. Disponível em:< http://www.infoesp.net/CAT_Reuniao_VII.pdf>. Acesso em 04 mai 2016.

COHEN, R. S. Cidade. Corpo e deficiência: percursos e discursos possíveis na experiência urbana. Programa de estudos interdisciplinares de comunidades e ecologia social (EICOS). Rio de Janeiro: UFRJ, 2006.

\section{DESIGN FOR ALL FOUNDATION. Design for} All is design tailored to human diversity. Publicado em: Designforall.org > What is Design For All? Disponível em: http://designforall.org/design.php. Acesso em: 23 fev 2016.

DUARTE, Cristiane Rose de Siqueira; COHEN, R. Afeto e Lugar: A Construção de uma Experiência Afetiva por Pessoas com Dificuldade de Locomoção. In Anais do Seminário Acessibilidade no Cotidiano. Versão em CD. Rio de Janeiro, 2004.

FRESTEIRO, R. H. A influência da iluminação: identificando barreiras. In: PRADO, A. R. de A.; ORNSTEIN, S. W. (Org). Desenho universal: caminhos da acessibilidade no Brasil. 1 ed. São Paulo: Annablume, 2010, p. 267-277.

LOUREIRO, E. P. Design Centrado no Usuário e as Limitações do Mercado de Produtos Interativos: Pesquisa e Análise Sobre Indicadores para uma Conciliação entre Pesquisa e Mercado. Belo Horizonte, 2008.

\section{LOWDERMILK, Travis. Design centrado no} usuário: um guia para o desenvolvimento de aplicativos amigáveis. São Paulo: Novatec Editora, 2013.

MELLO, M. Tecnologia assistiva. In: GREVE, J. M. D.; AMATUZZI, M. M. "Medicina de reabilitação aplicada à ortopedia e traumatologia". São Paulo: Manole, 1997.

NULL, Roberta. Universal Design: Principles and Models. CRC Press, Taylor \& Francis Group, 2013.

PRODINTEC. Guía Diseño para todos. $16^{\circ}$ Ergodesign - Congresso Internacional de Ergonomia e Usabilidade de Interfaces Humano Tecnológica: Produto, Informações Ambientes Construídos e Transporte

$16^{\circ}$ USIHC - Congresso Internacional de Ergonomia e Usabilidade de Interfaces Humano Computador

CINAHPA | 2017 - Congresso Internacional de Ambientes Hipermídia para Aprendizagem.

Publicado por Fundación Prodintec. Em: Início » Publicaciones. Disponível em:

<http://www.prodintec.es/catalogo/ficheros/aplicac iones/fichero_44_4441.pdf>. Acesso em: 24 mai 2016

RADABAUGH, M. P. NIDRR's Long Range Plan - Technology for Access and Function Research Section Two: NIDDR Research Agenda Chapter 5: TECHNOLOGY FOR ACCESS AND FUNCTION -Disponível em: <http://www.ncddr.org/rpp/techaf/lrp_ov.html> Acesso em: 24 mai 2016.

ROZICKI, C. Deficiente a participação nas esferas da vida em sociedade. Revista Espaço Acadêmico. Ano II. nº 22. Março 2003.

SONZA, Andréa Poletto (org) [et al.]. Material Didático, Acessibilidade e Tecnologia Assistiva: Pensando a Inclusão Sociodigital de PNEs, Bento Gonçalves, 2013.

STAINBACK, S., Stainback, W., East, K., \& Sapon-Shevin, M. A commentary on inclusion and the development of a positive self-identity by people with disabilities. Exceptional Children, 1994, p. 486-490.

THE CENTER FOR UNIVERSAL DESIGN. A Guide to Evaluating the Universal Design Performance of Products. N.C. State University, 2003.

WORLD HEALTH ORGANIZATION. A manual of classification relating to the consequences of disease. In: International Classification of Impairments, Disabilities, and Handicaps. Geneva, 1993.

\section{Agradecimentos}

Ao Conselho Nacional de Desenvolvimento Científico e Tecnológico - CNPq, e a Lucia pela persistência em incluir seu filho na sociedade. 